Proc. Indian Acad. Sci., Vol. 87 A (E \& P Sciences-4), No. 11, November 1978, pp. 235-243, (C) printed in India

\title{
Nature of magnetic grains in basalts and implications for palaeomagnetism
}

\author{
C RADHAKRISHNAMURTY, S D LIKHITE, E R DEUTSCH* \\ and G S MURTHY* \\ Tata Institute of Fundamental Research, Bombay 400005 \\ *Geomagnetic Research Laboratory, Physics Department, Memorial University of \\ Newfoundland, St. John's, Canada
}

MS roceived 3 July 1978; revised 4 September 1978

\begin{abstract}
Investigations involving temperature dependence of low-field susceptibility and of low- and high-field hysteresis have been carried out on more than one thousand basalt samples of ages ranging from less than 3 million years to more than 1 billion years. Combined application of these measurements makes it possible to distinguish rapidly the effective particle sizes and oxidation states of the magnetic minerals in the rock.

One interesting finding is that, in basalts of widely different ages, a strongly cationdeficient phase of magnetite having distinct magnetic properties predominates over other types of magnetic grains inferred to be present. Properties attributable to multidomain magnetite were found often in basalts older than Cretaceous, but seem to be present only occasionally among the younger basalts. Despite the fact of a frequent association of magnetite with titanium in basalts, results of our tests carried out on such basalts do not in general show a magnetic behaviour consistent with the magnetic material being a solid-solution titanomagnetite. Some implications of these results for palacomagnetism are discussed.
\end{abstract}

Keywords. Palaeomagnetism; single-domain; multidomain; superparamagnetic particles; basalts.

\section{Introduction}

It has been known from the very beginning of palacomagnetic investigations that some rocks possess a more stable remanent magnetization than others taken from the sama lava flow or dyke. Since palaeomagnetism is mainly concerned with the stable and consistent direction of a suite of rocks, the usual emphasis is to apply a proper magnetic cleaning technique to obtain a satisfactory remanent direction. It is not uncommon for some or all samples from a site showing scattered direction even after cleaning and usually such cases are omitted, without any reason, for computing the average direction. We propose here that certain effects caused by alteration of magnetic mineral grains could explain the observed scatter in many cases.

The mineralogy of rock magnetism is considered to be complicated (Nicholls 1955 ) in view of the diversity of magnetic minerals and their solid solutions in rocks. Variations in the domain states of the minerals and their mixtures could further complicate the understanding of their magnetic properties. In view of this complexity

\footnotetext{
* Presented at the IAGA/IAMAP Joint Assembly session on 'rock magnetism', Seattle, Washington, August 1977.
} 
it is not too surprising that attempted explanations of the overall magnetic granulometry of rocks have been generally unsuccessful. Some attempts to study the granulometry of basalts (Radhakrishnamurty and Likhite, 1970; Radhakrishnamurty et al 1972) have pointed to the existence of a simpler scheme of minerals and their domain states than had been anticipated. This has led to the development of a granulometric technique (Radhakrishnamurty and Deutsch 1974; Radhakrishnamurty et al 1977) which has here been applied to a total of 1042 samples of basalts obtained from different parts of the world. The results indicate that the magnetic behaviour of most of these basalts may be explained in terms of almost pure grains of magnetite and of its domain and oxidation states. To some extent, such an understanding of magnetic granulometry might furnish clues to the evolution of different magnetic states in basalts. This has a number of possible implications for palaeomagnetism.

\section{Iron oxide grains in basalts}

The iron oxide grains in basalts usually contain substantial amounts of titanium and thus should form minerals of the titanomagnetite series. However, studies by magnetic methods (Radhakrishnamurty, et al in preparation) have indicated that the observed magnetic properties rarely correspond to those expected for titanomagnetites. Moreover, a magnetic behaviour attributable to the presence of superparamagnetic particles has been inferred in basalt samples from several formations, despite the fact that the physical size of the iron oxide grains in the rock is much larger than required to form multidomains (e.g. Deutsch and Patzold 1976; and Table 2, first entry). These two significant observations have raised doubts regarding some of the accepted concepts in rock magnetism.

Methods of studying the basic property of hysteresis at different magnetic fields and temperatures were used extensively to deduce the domain states of the magnetic grains in basalts. While it is extremely rare to find hysteresis properties corresponding to those theoretically expected (Bean 1955) for exclusively multidomain (MD), single domain (SD) or superparamagnetic (SP) particles dispersed in a non-magnetic matrix, the majority of hysteresis loops of basalts are found to correspond to mixtures of the different domain states (Radhakrishnamurty et al 1972). However, the observed magnetic properties of basalts cannot be fully explained only in terms of the three above-mentioned domain states. Radhakrishnamurty et al (1971) found it necessary to invoke the presence of a highly cation-deficient phase of singledomain magnetite $(C D)$ in order to explain the magnetic behaviour of columnar basalts in India. Later granulometric studies, for example on the basalts from Leg 37 of the Deep Sea Drilling Project (Murthy et al 1976; and table 2, second entry) have indicated that this magnetic mineral phase is as common as the three "unoxidised ' magnetic domain states. In general, the $C D$ phase may be similar to the phase attributed to high-temperature oxidation by Strangway et al (1968) but is to be contrasted, both with respect to its mode of origin and its magnetic properties, with the end-product of regional hydrothermal alteration at low to medium temperatures (Johnson and Merrill 1974).

Figure 1 shows typical hysteresis loops and, in schematic form, the thermal variation of susceptibility ( $k-T$ curves) for basalt samples inferred to contain a very high proportion of SP, SD, MD and strongly cation-deficient (CD) states of magnetic 

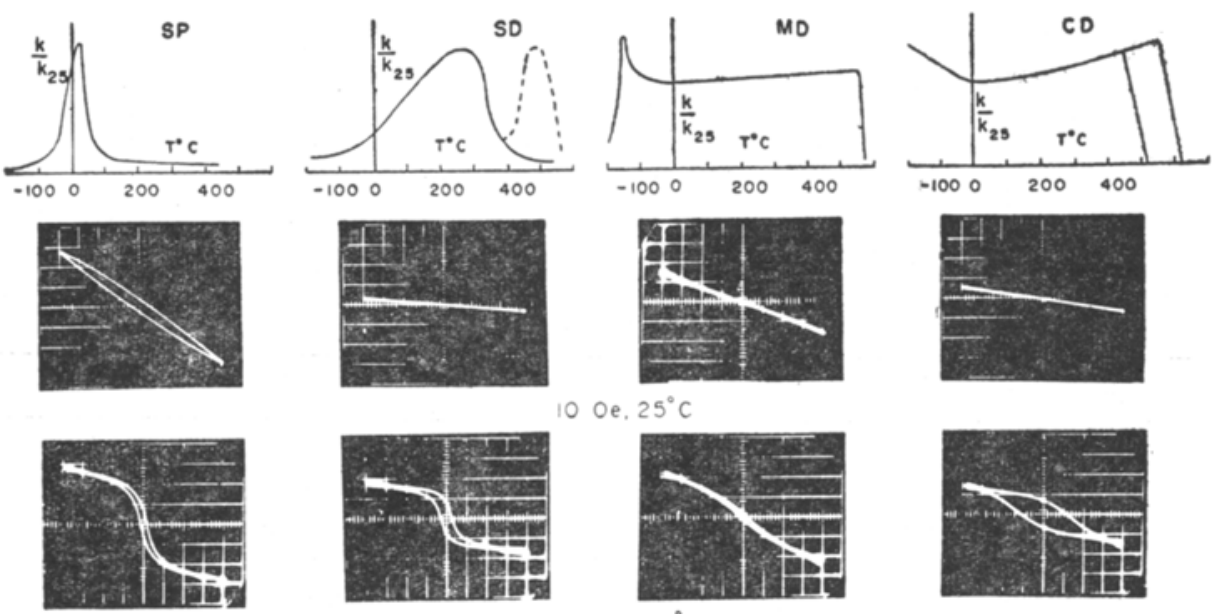

10 Oe, $25^{\circ} \mathrm{C}$
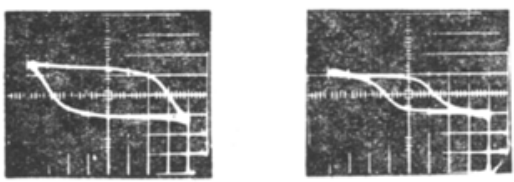

15000 e. $25^{\circ} \mathrm{C}$
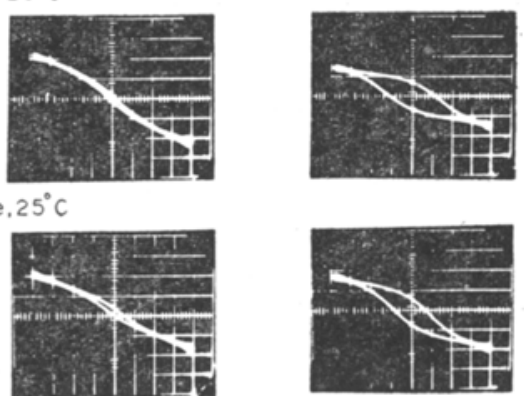

15000 e, $-196^{\circ} \mathrm{C}$

Figure 1. Low-field susceptibility vs temperature curves and corresponding hysteresis loops at different fields and temperatures for basalts containing magnetite predominantly in the superparamagnetic (SP), singledomain (SD), multidomain (MD) and cation-deficient (CD) states as defined in text. The hysteresis loops are from actual rock samples; the $k-T$ curves are schematic but resemble cases of $k-T$ curves obtained from rock samples.

grains. Each of these four domain or oxidation states gives distinct expression to the associated hysteresis loops and $k-T$ curves by which the states can be identified. These characteristic features are summarised in table 1 . The values of the susceptibilities at $-196^{\circ} \mathrm{C}$ and at $-150^{\circ} \mathrm{C}$, each normalised to $25^{\circ} \mathrm{C}$, are empirically deduced from observations on hundreds of basalts and are based on additional measurements made subsequently to an earlier report (Radhakrishnamurty et al 1977).

The CD state in natural rocks has some peculiar properties; its $k_{-196} / k_{25}$ value is $1 \cdot 5$, compared to the values for other states which are much less than unity; and its coercive force is smaller at low temperatures than at $25^{\circ} \mathrm{C}$, while the opposite is the case for the other three states. These characteristics of $C D$ are experimental facts for which an explanation based on the more fundamental properties such as crystal structure has not yet been found. Experiments reveal that different samples containing CD material which show $k_{-186} / k_{25}$ values close to 1.5 become non-magnetic at temperatures anywhere between 500 and $620^{\circ} \mathrm{C}$. The CD state seems to correspond to a composition close to that of magnetite, the spread in the 'apparent' Curie point being caused by grain size effects and/or small impurities of $T i$ in the samples concerned. There are experimental difficulties in confirming these inferences.

The above conclusions were drawn indirectly from experimental observations on heating CD samples. Figure 2 schematically shows the susceptibility changes that usually take place upon heating samples containing magnetite in the SD and CD states. Basalts which show SD properties in their virgin state often exhibit strongly 
Table 1. Characteristic data for different states of magnetite grains, empirically deduced from observations on several hundred basalt samples. Susceptibility values at $-196^{\circ} \mathrm{C},-150^{\circ} \mathrm{C}\left(k_{-196}, k_{-160}\right)$ are nommalised to $25^{\circ} \mathrm{C}$. The $k_{-160} / k_{\text {s5 }}$ value is quoted only in the case of $\mathrm{MD}$, where a $k$-peak corresponding to the magnetite transition $\left(-155^{\circ} \mathrm{C}\right)$ is observed. MD-multidomain, SD-singledomain, CD-cation-deficient state of (presumably 'SD'-sized) magnetite, SP-superparamagnetic. 'Rayleigh loop' denotes the presence or absence of a hysteresis loop in $1 \mathrm{mT}(10 \mathrm{Oe}) . J_{\mathrm{r}}, J_{m}$ are the remanent and maximum intensities of the samples in $150 \mathrm{mT}(1500 \mathrm{Oe})$.

\begin{tabular}{ccccccc}
\hline Grain state & $K_{-196} / k_{25}$ & $\begin{array}{c}K_{150} / k_{85} \\
\text { (Peak if any) }\end{array}$ & Rayleigh loop & \multicolumn{2}{c}{$J_{r} / J_{m}$} \\
\hline 1 & 2 & 3 & 4 & 5 & \multicolumn{1}{c}{6} \\
\hline MD & 0.3 & 1.5 & No & $<0.2$ & $<0.2$ \\
SD & 0.2 & - & No & 0.5 & 0.8 \\
CD & 1.5 & - & No & $<0.5$ & $<0.5$ \\
SP & 0.05 & - & Yes & $<0.2$ & 0.8 \\
\hline
\end{tabular}

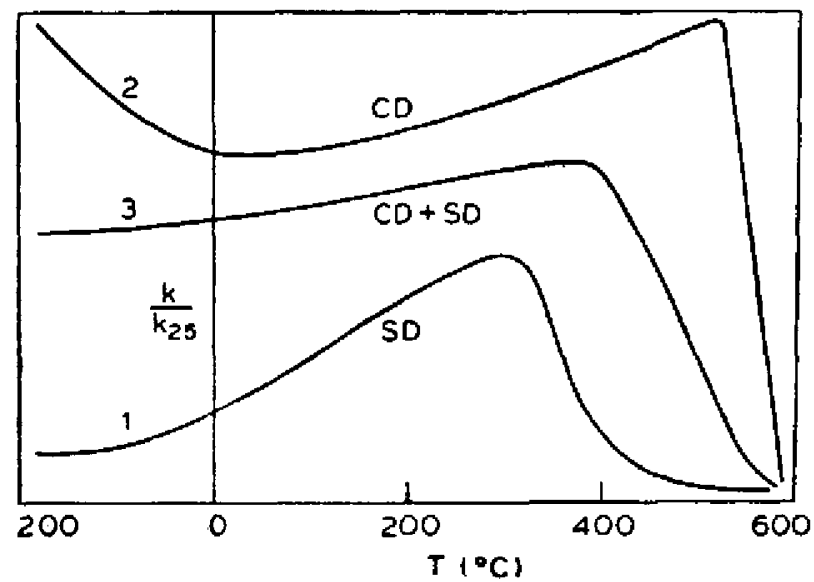

Figure 2. Schematic $k-T$ curves expected for basalts containing cation-deficient (CD) and essentially stoichiometric singledomain (SD) states of magnetic grains and their mixtures (CD + SD).

cation-deficient behaviour after completion of a heating-cooling cycle. The opposite behaviour (change from $\mathrm{CD}$ to SD properties) is also commonly observed. Thus, in a $k-T$ experiment a sample behaving in accordance with curve 1 (figure 2) on heating would tend to follow curve 2 while cooling, and one that corresponds to curve 2 on heating would follow curve 1 on cooling. However, such ideal cases require a complete change of SD to $\mathrm{CD}$ or $\mathrm{CD}$ to $\mathrm{SD}$ and are quite rare, whereas the production of ' mixed '-component states by heating samples that had been in a predominantly 'pure' state is quite common, for example in the case of CD or SD samples each changing to $\mathrm{CD}+\mathrm{SD}$ (figure 2, curve 3 ). The designation ' $\mathrm{CD}+\mathrm{SD}$ ' is used here qualitatively to denote the result that suitable magnetic tests have shown both states to be significantly present in the same sample, although generally the state listed first (CD in this case) is magnetically the more prominent. These changes on heating might be explained on the basis of fine grains of magnetite changing to a CD state by oxidation and CD magnetite grains changing to magnetite and hematite by 'disproportionation ' according to the mechanism proposed by Feitknecht and Gallagher 
(1970). Since the conversion of magnetite to maghemite requires highly controlled conditions that could be seldom expected to prevail during either the formation or the heating of basalts, a CD state of magnetite having the observed properties and which is fairly stable seems to be the normal product.

The SP state as conceived in this scheme implies the presence of grains of magnetite with or without minor Ti impurity, having blocking temperatures $\left(T_{b}\right)$ close to atmospheric temperature and behaving like optimum SD material when cooled to lower temperatures. Thus, in such samples, $k_{-196} / k_{25}$ values are very small (table 1 ). However, in some basalts, especially altered ones, $k_{-108} / k_{25}$ was found to exceed $1 \cdot 5$, reaching values as high as 5 . From this result we inferred the presence of grains that are superparamagnetic down to and below $-196^{\circ} \mathrm{C}$. Some of these samples show also other very interesting magnetic properties as reported earlier (Radhakrishnamurty et al 1973), and we have denoted their state as $\mathrm{SP}^{+}$.

The MD state represents multidomain grains of magnetite showing the characteristic $k$-peak at about $-155^{\circ} \mathrm{C}$ arising from the isotropic point at that temperature. But our observations on a large number of samples have indicated that the $k$-peak can occur anywhere in the temperature range -165 to $-150^{\circ} \mathrm{C}$, possibly due to shifts in the isotropic points of the grains because of low concentrations of $T i$ in them (Syono and Ishikawa 1963). All such cases have been grouped under MD without distinction.

Thus it appears that the four basic domain and oxidation states (SP, SD, MD and CD) may be identifiable magnetically in any collection of basalts. Since any one of the four states is closely related to the others through processes like grain growth, grain subdivision and oxidation, it is only natural to expect basalts typically to contain grains of different states mixed together. Figure 3 shows in schematic form the lowtemperature $k-T$ curves of some mixed states which have proved to be easy to identify. The observed value of $k_{-196} / k_{25}$ for a basalt may lie anywhere between the limits of the pure SP and CD values $(0.05$ to 1.50 , table 1$)$, so that samples not in the 'pure' state will normally exhibit complex $k-T$ curves and hysteresis properties corresponding to the mixed states. Samples showing the magnetic behaviour attributable to a

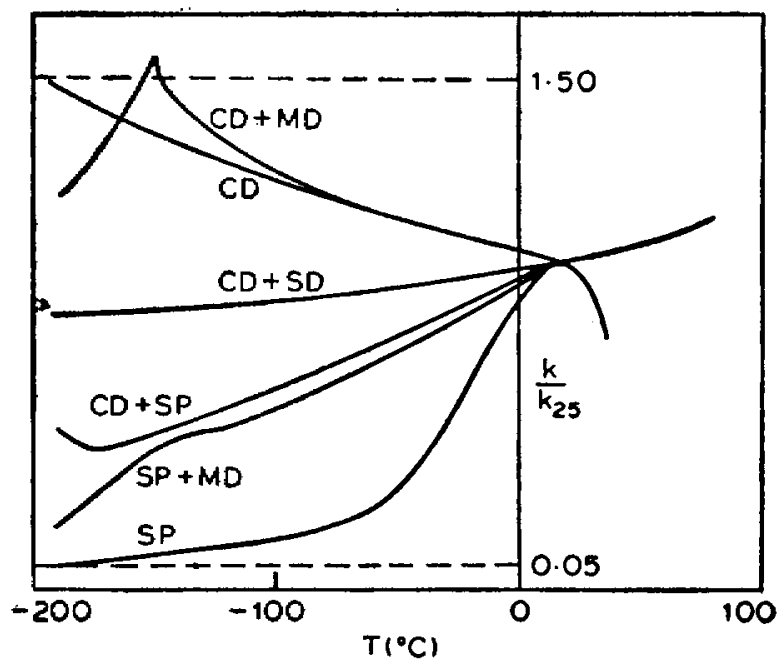

Figure 3. Schematic low-temperature $k$ - $T$ curves expected for basalts containing some mixtures of magnetite grains in different domain or oxidation states. 
mixture of three states are quite common, and while even cases of all four states coexisting in a single sample probably occur, a mixture of three states can adequately explain the observable behaviour of most of the samples. In summarising below the results of observations we must emphasise, however, that while the chief strength of the granulometric method lies in providing a quick as well as sharply discriminatory test of magnetic states present in basalts, the technique is essentially qualitative even when only two of the basic states are present. Nevertheless, it should be pointed out that the approximate quantitative method reported earlier (Radhakrishnamurty et al 1977), using the revised values given in table 1 of this paper, could still provide a convenient way of representing the mixed-states of basalts.

\section{Granulometry of basalts}

The granulometry of 1042 samples belonging to different basalt formations of the world has been studied. From the overall magnetic behaviour of a sample it is fairly easy to infer the particular state that is dominant and one or two other states that may be present in detectable amounts. For the purpose of this kind of analysis, 61 cases of $\mathrm{SP}^{+}$encountered in the total number of samples studied have been omitted, since the behaviour characterised as $\mathrm{SP}^{+}$will tend to mask the magnetic properties which other components would exhibit in the absence of $\mathrm{SP}^{+}$, and hence an $\mathrm{SP}^{+}$ component will not easily allow other dominant or detectable states to be properly identified.

The percentages of the remaining 981 samples in which a certain state is dominant and others are detectable have been computed and are given in table 2 . The most striking result is that nearly two-thirds of all samples are dominantly cation-deficient. Also it is interesting to note that the percentage of samples in which the MD state is dominant among younger (less than Cretaceous) basalts is nil or very small, whereas it is quite large in older basalts. The SP state is prevalent in several of the younger basalts. The detectability of an SP component in conjunction with a dominant MD component is technically difficult and hence the zero percentages shown for the SP state in the case of some of the older basalts may be somewhat erroneous. However, many of the 61 cases of $\mathrm{SP}^{+}$observed and excluded from table 2 came from older basalts.

\section{Formation of domain states in basalts}

The data presented in table 2 raise several questions, answers to which may have to be speculative for the time being, mainly because of experimental difficulties in attempting to provide the answers. The main question pertains to the widespread occurrence of the SP state in basalts. The total absence of observed magnetic properties consistent with multidomain titanomagnetite in basalts (Radhakrishnamurty et al in preparation), along with the frequent presence of an SP state, both conclusions being inferences based on magnetic techniques in basalts whose iron oxide grains contain substantial amounts of $\mathrm{Ti}$, indicate that submicroscopic exsolution of Ti is a possible cause of both the observations. Also, when the SD state is dominant in a basalt the maximum blocking temperature rarely exceeds $300^{\circ} \mathrm{C}$, and 
Table 2. Magnetic granulometry data for basalts of different ages. For definitions of domain and oxidation states (MD, CD, SD, SP), see table 1 and text. Samples usually exhibited a mixed character, the dominant state being shown without brackets, and one or more additional states of the grains being detectable, in which case the figure shown in brackets represents the approximate percentage of samples inferred in the subordinate state. 61 samples showing $\mathrm{SP}^{+}$properties have been omitted from the table.

\begin{tabular}{|c|c|c|c|c|c|c|}
\hline \multirow[t]{2}{*}{ Formation or source } & \multirow{2}{*}{ Age } & \multirow{2}{*}{$\begin{array}{l}\text { Number } \\
\text { or } \\
\text { Samples }\end{array}$} & \multicolumn{4}{|c|}{$\begin{array}{l}\text { Percentage of samples in which a } \\
\text { state is dominant or (detectable) }\end{array}$} \\
\hline & & & $\mathrm{MD}$ & $\mathrm{CD}$ & SD & $\mathbf{S P}$ \\
\hline $\begin{array}{l}\text { Leg, 34, DSDP } \\
\text { Leg, 37, DSDP } \\
\text { Columbia River basalts, USA } \\
\text { W. Iceland basalts }\end{array}$ & $\begin{array}{l}15,30 \& 40 \text { million years } \\
3 \cdot 5,10 \& 13 \text { million years } \\
\text { Mjocene } \\
12 \text { million years }\end{array}$ & $\begin{array}{r}37 \\
18 \\
8 \\
21\end{array}$ & $\begin{array}{l}0(0) \\
6(0) \\
0(0) \\
0(19)\end{array}$ & $\begin{array}{r}0(16) \\
39(55) \\
62(38) \\
81(19)\end{array}$ & $\begin{array}{l}16(84) \\
50(45) \\
38(62) \\
19(62)\end{array}$ & $\begin{array}{l}84(16) \\
6(0) \\
0(100) \\
0(47)\end{array}$ \\
\hline $\begin{array}{l}\text { Hungty basalts } \\
\text { UK basalts \& dykes } \\
\text { Italy basalts } \\
\text { Kenya basalts }\end{array}$ & $\begin{array}{l}\text { Tertiary } \\
\text { Tertiary } \\
\text { Tertiary } \\
\text { Miocene }\end{array}$ & $\begin{array}{r}4 \\
102 \\
36 \\
107\end{array}$ & $\begin{array}{l}0(0) \\
4(17) \\
0(14) \\
1(24)\end{array}$ & $\begin{array}{l}75(25) \\
64(28) \\
61(5) \\
78(18)\end{array}$ & $\begin{array}{l}0(100) \\
24(70) \\
19(72) \\
13(72)\end{array}$ & $\begin{array}{r}25(75) \\
8(50) \\
20(27) \\
8(37)\end{array}$ \\
\hline $\begin{array}{l}\text { Disko basalts, Greenland } \\
\text { Deccan traps, India } \\
\text { DT. Dykes, India } \\
\text { Rajmahal traps, India }\end{array}$ & $\begin{array}{l}\text { Tertiary } \\
60-65 \text { million years } \\
60-65 \text { million years } \\
\text { Cretaceous }\end{array}$ & $\begin{array}{r}46 \\
297 \\
35 \\
80\end{array}$ & $\begin{array}{l}0(39) \\
0(37) \\
O(57) \\
0(0)\end{array}$ & $\begin{array}{l}98(2) \\
96(2) \\
97(0) \\
61(39)\end{array}$ & $\begin{array}{r}2(85) \\
2(80) \\
3(60) \\
39(61)\end{array}$ & $\begin{array}{l}O(15) \\
2(38) \\
0(15) \\
0(75)\end{array}$ \\
\hline $\begin{array}{l}\text { RT. Dykes, India } \\
\text { Hungary basalts } \\
\text { Scotland basalts } \\
\text { Nfd. ophiolites }\end{array}$ & $\begin{array}{l}\text { Cretaceous } \\
\text { Cretaceous } \\
\text { Carboniferous } \\
\text { Ordovician }\end{array}$ & $\begin{array}{r}19 \\
4 \\
25 \\
30\end{array}$ & $\begin{array}{l}0(5) \\
0(0) \\
0(25) \\
87(13)\end{array}$ & $\begin{array}{l}51(49) \\
75(25) \\
92(4) \\
10(87)\end{array}$ & $\begin{array}{r}49(51) \\
25(75) \\
4(75) \\
3(93)\end{array}$ & $\begin{array}{l}0(89) \\
0(75) \\
4(28) \\
0(0)\end{array}$ \\
\hline $\begin{array}{l}\text { Seychelles dolerites } \\
\text { Bijiwar traps, India } \\
\text { Cuddapah traps, India } \\
\text { Basic dykes, India }\end{array}$ & $\begin{array}{l}\text { Precam, \& Ter. } \\
\text { Precambrian } \\
\text { Precambrian } \\
\text { Precambrian }\end{array}$ & $\begin{array}{r}24 \\
6 \\
70 \\
12\end{array}$ & $\begin{array}{l}66(12) \\
83(0) \\
83(17) \\
92(8)\end{array}$ & $\begin{array}{r}21(79) \\
17(83) \\
13(63) \\
3(92)\end{array}$ & $\begin{array}{l}3(87) \\
0(0) \\
4(94) \\
0(83)\end{array}$ & $\begin{array}{r}10(4) \\
0(0) \\
0(0) \\
0(0)\end{array}$ \\
\hline
\end{tabular}

more often the SP and SD states occur together. These observations point out that the spectrum of SP and SD grains spans only a rather narrow size range and that it comprises those grains the bulk composition of which corresponds to Ti-rich titanomagnetite. This conjecture also implies that titanomagnetities might be mineralogically unstable and that the resulting SP and SD states are somehow stable, possibly residing in the core of the large grains.

\section{Implications for palaeomagnetism}

The processes envisaged in the foregoing section may appear detrimental to palaeomagnetism whose main requirement is the presence in rocks of iron oxide grains that acquire at their formation a remanence which remains unchanged. However, the fortuitous relationship between the SD and CD states seems to have the tendency of preserving the original directions of magnetization to a large extent. From studies on synthetic micropowders of magnetite, Johnson and Merrill (1974) have shown that, possibly through a process of positive exchange coupling, singledomain grains of magnetite are able to retain the original direction of magnetisation even after oxidation. Large grains (MD) appear to be less suited to follow such a process. 
Since not all the palaeomagnetic data for the formations listed in table 2 were available to us, a systematic attempt to correlate their granulometry with palaeomagnetism was not made. However, the following few specific cases deserve comment.

In rocks from the Rajmahal traps, the $\mathrm{CD}$ and $\mathrm{SD}$ states dominate while $\mathrm{MD}$ is virtually absent, and this formation has shown a minimum of scatter in its palaeomagnetic directions among various sites; on the other hand, the samples from the Deccan traps, with $37 \%$ of them having a detectable MD state, showed much larger scatter (Murty and Sahasrabudhe, 1971).

No meaningful palaeomagnetic results could be obtained from the Cuddapah traps (Athavale et al 1963) and Seychelles dolerites (Matthews and Reilly 1964) wherein the MD state dominates. (All Seychelles samples were treated together, for although they had been collected from both Precambrian and Tertiary dykes, they were made available to us without age being specifed). Hence we propose that an evolutionary process may be in effect here, whereby the formation of new multidomain grains in pre-existing basalts will cause the prevailing, stable remanence directions of a suite to become more dispersed, as expected from the association of the MD state with low coercive force. This inference, however, needs further study.

In view of the above observations and discussions, the fact that about $80 \%$ of all samples in table 2 were found to be dominant in the CD and SD states, and only $20 \%$ in the MD and SP states, is of some practical importance in supporting the view that, in general, one may expect a wide range of basaltic rocks to be suitable for palaeomagnetism. At the same time, the proper interpretation of palaeomagnetic results clearly requires a knowledge of the domain and oxidation states, along with exercise of much caution.

\section{Acknowledgements}

We thank Professors R L Wilson, H Soffel, P K S Raja and P V Sharma for giving us samples from their respective rock collections. The work at Memorial University of Newfoundland was supported by operating grants to ERD and GSM from the National Research Council of Canada.

\section{References}

Athavale R N, Radhakrishnamurty C and Sahasrabudhe P W 1963 Geophys. J. R. Astron. Soc. 7 304

Bean C P 1955 J. Appl. Phys. 261381

Deutsch E R and Patzold R R 1976 J. Geophys. Res. 814188

Feitknecht W and Gallagher K G 1970 Nature London 228548

Johnson H P and Merrill R T 1974 J. Geophys. Res. 795533

Matthews D H and Reilly T A 1964 Nature London 2301160

Murty C R K and Sahasrabudhe P W 1971 Bull. Volcan. 35-3 736

Murthy G S, Deutsch E R and Patzold R R 1976 J. Geophys. Res. 814199

Nicholls G D 1955 Adv. Phys. 4113

Radhakrishnamurty C and Deutsch E R $1974 \mathrm{~J}$. Geophys. 40453

Radhakrishnamurty C, Deutsch $\mathbf{E} R$ and Murthy $\mathbf{G} S$ (in preparation)

Radhakrishnamurty C and Likhite S D 1970 Earth Planet. Sct. Lett. 7389 
Radhakrishnamurty C, Likhite S D, Raja P K S and Sahasrabudhe P W 1971 Nature London Phys. Sci. 23533

Radhakrishnamurty C, Likhite S D and Sahasrabudhe P W 1977 Phys. Earth Planet. Int. 13289

Radhakrishnamurty C, Raja P K S, Likhite S D and Sahasrabudhe P W 1972 Pure Appl. Geophys. 93129

Radhakrishnamurty C, Sastry N P and Deutsch E R 1973 Pramana 161

Strangway D W, Larson E E and Goldstein M 1968 J. Geophys. Res. 733787

Syono Y and Ishikawa Y 1963 J. Phys. Soc. Jpn. 181230 